\title{
Práticas experimentais no ensino de física nuclear utilizando material de
} baixo custo ${ }^{+*}$

Cleber Adelar Boff

Rodrigo Oliveira Bastos ${ }^{2}$

Universidade Estadual do Centro-Oeste

Guarapuava - PR

Fábio Luiz Melquiades ${ }^{3}$

Departamento de Física - Universidade Estadual de Londrina

Londrina - Paraná

\section{Resumo}

Uma das dificuldades para o Ensino de Física Moderna é a pouca difusão da experimentação, principalmente para o ensino de Física Nuclear, seja no Ensino Médio ou no Superior. As atividades sugeridas na literatura geralmente simbolizam o fenômeno real através de simulações. Isso acontece, pois as práticas experimentais, geralmente, envolvem algum tipo de detector de radiação de custo elevado e uma fonte de radiação ionizante que requer cuidados especiais de manuseio e armazenagem, sendo sujeita a regulamentação altamente burocrática no Brasil. O presente trabalho supera estas dificuldades e propõe duas práticas de Física Nuclear experimental utilizando uma câmara de ionização de baixo custo: a medida de filhos do Radônio-222 coletados do ar de ambientes fechados, e a medida do alcance de partículas alfa emitidas pelos filhos do Tório-232 presentes em camisinhas de lampião. O artigo mostra os procedimentos experimentais e os resultados esperados, indicando que as práticas podem servir de suporte para aulas de Física Nuclear.

\footnotetext{
${ }^{+}$Experimental practices in the teaching of Nuclear Physics using low cost material

* Recebido: fevereiro de 2016.

Aceito: dezembro de 2016.

1 E-mail: cleberfisic@gmail.com

2 E-mail: bastosrodrigoo@yahoo.com.br

3 E-mail: melquiades.fabio@gmail.com
} 
Palavras-chave: Física moderna; Instrumentação nuclear; Fontes radioativas; Ensino de Física Nuclear.

\begin{abstract}
One of the difficulties in Modern Physics teaching is the little widespread of experimental activities. This is particularly true for teaching nuclear physics in Brazilian high school or college. The activities suggested in the literature generally symbolize the real phenomenon, using simulations. It happens because the experimental practices, generally, include some kind of expensive radiation detector and an ionizing radiation source that requires special care for handling and storage, being subject to a highly bureaucratic regulation in Brazil. This paper overcomes these difficulties and proposes two nuclear physics experiments using a low-cost ion chamber: the measurement of Radon-222 daughters collected from the indoor air, and the measurement of the range of alpha particles emitted by the Thorium-232 daughters present in lantern mantles. The article presents the experimental procedures and the expected results, indicating that the experiments may provide support for nuclear physics classes.
\end{abstract}

Keywords: Modern Physics; Nuclear instrumentation; Radiation sources; Nuclear Physics teaching.

\title{
I. Introdução
}

A introdução da Física Moderna no Ensino Médio tem sido motivo de estudos de vários pesquisadores, visando sanar dificuldades encontradas na compreensão dos fenômenos ligados à Física Moderna.

Muitas vezes a experimentação em Física Moderna fica em segundo plano, e entre os principais motivos está a falta de local adequado e a falta de preparo dos professores associada à dificuldade em encontrar experiências de Física Moderna de baixo custo.

De acordo com Silva (2012), apesar de ser considerado um importante complemento, as atividades experimentais de Física Nuclear são de difícil acesso, sendo raramente encontradas.

Neste caso específico da Física Nuclear as fontes utilizadas no ensino devem ser seladas, devem possuir meia-vida curta e ou atividades que não requerem maiores cuidados referentes à proteção radiológica, pois deverão ser manipuladas pelos alunos. No caso dos detectores a serem utilizados nos experimentos didáticos, devem ser acessíveis aos vários níveis de ensino e sensíveis o suficiente para medir a radiação dessas fontes. 
Este artigo tem por objetivo propor práticas de Física Nuclear utilizando material de baixo custo, com o intuito de facilitar o ensino de Física Nuclear em todas as esferas de ensino e sugerir fontes radioativas de baixa intensidade ou meia vida curta, para instrumentação em ensino de Física Nuclear.

Para a realização das práticas foi utilizada, como detector, uma câmara de ionização gasosa, baseada na proposta de Wenzel (WENZEL, 2014), ligeiramente modificada (BOFF; BASTOS; MELQUIADES, 2014). A montagem desta câmara utiliza poucos materiais e um circuito amplificador simples (dois ou três transistores em configuração Darlington). A câmara mostrou sensibilidade e estabilidade suficientes para a execução das práticas aqui apresentadas. Os detalhes da montagem podem ser verificados no artigo de Boff, Bastos e Melquiades (2014) e também na dissertação de mestrado profissional de Boff (2016).

Dois experimentos são propostos utilizando a câmara de ionização de baixo custo: a medida de filhos do Radônio-222 coletados do ar de ambientes fechados; e a medida do alcance de partículas alfa emitidas pelos filhos do Tório-232 presentes em camisinhas de lampião.

A seguir, são apresentados alguns fundamentos sobre Física Nuclear com o objetivo de servir de suporte para o entendimento das duas práticas propostas. Na sequência, as experiências e os resultados esperados para cada uma delas são mostrados, indicando que as mesmas podem servir de suporte para aulas de Física Nuclear.

\section{Fundamentos de Física Nuclear}

\section{II.1 Decaimento radioativo, tipos de radiação e séries radioativas}

Os núcleos instáveis, denominados de radioativos, possuem nucleons (prótons e nêutrons) em um estado de maior energia, podendo sofrer o chamado decaimento radioativo, com objetivo de atingir a estabilidade. Os processos radioativos seguem uma lei de desintegração exponencial, ou seja, o número de núcleos radioativos decresce continuamente à medida que alguns dos núcleos se desintegram, sendo a taxa de decaimento proporcional ao número de núcleos radioativos presentes.

Uma forma de decaimento radioativo é o decaimento alfa $(\alpha)$, que ocorre em núcleos de número atômico maior que 82 , onde um núcleo pai instável decai nos núcleos filhos através da emissão de uma partícula $\alpha$, que é um núcleo de Hélio, ${ }^{2} \mathrm{He}^{4}$.

Em um decaimento alfa, a massa atômica diminui em 4 e o número atômico diminui em 2. Esse decaimento pode ocorrer espontaneamente, pois a soma das massas dos produtos da reação é menor que a massa do núcleo pai, sendo a diferença de massa convertida em energia cinética dos produtos do decaimento.

Outra forma de um núcleo atingir a estabilidade é com o decaimento $\beta$ (beta), que ocorre quando um núcleo se transforma em núcleo diferente emitindo um elétron ou um pósitron (partícula de carga positiva com a mesma massa do elétron), ou ainda capturando um elétron da eletrosfera, decaimento este denominado captura eletrônica. As partículas beta 
emitidas pelo núcleo em decaimentos radioativos são de alta energia. A maioria das energias beta são menores de $2 \mathrm{MeV}$, mas há alguns emissores de partículas beta com energias mais elevadas.

Geralmente, associado ao decaimento $\beta$, existe a emissão de fótons de alta energia por parte do núcleo filho, que busca a estabilidade. Estes fótons são denominados raios gama. Em um decaimento gama, tanto o número de massa quanto o número atômico dos núcleos permanecem os mesmos.

Em muitos casos, após ocorrer um dos tipos de desintegração descritos anteriormente, o processo radioativo se completa. Em outros, o núcleo filho também é radioativo, decaindo outro núcleo, que também pode ser radioativo. À sequência de decaimentos deste tipo, que pode incluir vários núcleos radioativos que decaem em série, um no outro, é denominada série radioativa.

De acordo com CNEN (2003), há quatro séries de desintegração, sendo três famílias radioativas naturais, conhecidas como: Série do Urânio $(4 n+2)$, Série do Actínio (4n+3) e Série do Tório $(4 n+0)$. A Série do Netúnio $(4 n+1)$ não é encontrada na natureza e foi criada em laboratório.

Nas séries de decaimento radioativo, o único tipo de decaimento que altera o número de prótons e nêutrons conjuntamente (número de nucleons) contidos no núcleo é a emissão alfa, que reduz seu número de massa em quatro. Assim, o número de nucleons múltiplo de 4 é preservado através de qualquer cadeia de decaimento. Isso leva à quatro séries de decaimento radioativo possíveis, com massas atômicas: $4 n+0,4 n+1,4 n+2$ e $4 n+3$, onde n é o número inteiro múltiplo de 4 , resultante da divisão do número de massa de um nuclídeo particular pelo número de massa da partícula alfa, e o "resto" da divisão fornece os números $0,1,2$ e 3.

Como exemplo, a série $4 \mathrm{n}$ tem número de massa que pode ser escrito como $\mathrm{A}=4 \mathrm{n}$, com $\mathrm{n}$ inteiro, começando com o núcleo de Tório-232, para o qual $\mathrm{n}=58$. Tabela 1 mostra os núcleos da série $4 \mathrm{n}$ e os correspondentes decaimentos.

Tabela 1 - Propriedades de decaimento detalhada da série do $\mathrm{Th}^{232}$.

\begin{tabular}{|c|c|c|c|c|c|}
\hline Nuclídeo & $\begin{array}{c}\text { energia } \alpha \\
(\mathrm{MeV})\end{array}$ & $\begin{array}{c}\text { energia } \beta \\
(\mathrm{MeV})\end{array}$ & $\begin{array}{c}\text { intensidade } \\
(\%)\end{array}$ & $\begin{array}{c}\text { energia } \gamma \\
(\mathrm{MeV})\end{array}$ & $\begin{array}{c}\text { intensidade } \\
(\%)\end{array}$ \\
\hline${ }^{90} \mathrm{Th}^{232}$ & 3,95 & & 24 & 0,059 & \\
\hline & 4,01 & & 76 & & \\
\hline${ }^{88} \mathrm{Ra}^{228}$ & & 0,024 & 30 & 0,010 & \\
\hline & & 0,04 & 70 & & \\
\hline${ }^{89} \mathrm{Ac}^{228}$ & & 0,45 & 13 & 0,058 & \\
\hline & & 0,64 & 7,6 & 0,129 & 4,1 \\
\hline & & 1,11 & 53 & 0,209 & 1 \\
\hline & & 1,70 & 6,7 & 0,270 & 3 \\
\hline
\end{tabular}




\begin{tabular}{|c|c|c|c|c|c|}
\hline & & 1,85 & 9,6 & 0,328 & 4 \\
\hline & & 2,18 & 10,1 & 0,338 & 11 \\
\hline \multirow[t]{2}{*}{${ }^{90} \mathrm{Th}^{228}$} & 5,34 & & 28 & 0,084 & 1,6 \\
\hline & 5,43 & & 71 & & \\
\hline \multirow[t]{2}{*}{${ }^{88} \mathrm{Ra}^{224}$} & 5,45 & & 6 & 0,241 & 3,7 \\
\hline & 5,68 & & 94 & & \\
\hline${ }^{86} \mathrm{Rn}^{220}$ & 6,29 & & 100 & & \\
\hline${ }^{84} \mathrm{Po}^{216}$ & 6,78 & & 100 & & \\
\hline \multirow[t]{3}{*}{${ }^{82} \mathrm{~Pb}^{212}$} & & 0,154 & 5 & 0,115 & \\
\hline & & 0,331 & 81 & 0,239 & 47 \\
\hline & & 0,569 & 14 & 0,300 & 3,2 \\
\hline \multirow[t]{6}{*}{${ }^{83} \mathrm{Bi}^{212}$} & 6,05 & & 23,5 & 0,040 & 2 \\
\hline & 6,09 & & 9 & 0,727 & 7,1 \\
\hline & & 0,67 & 2,2 & 0,785 & 1,1 \\
\hline & & 0,93 & 1,4 & 1,620 & 1,8 \\
\hline & & 1,55 & 5 & & \\
\hline & & 2,27 & 54 & & \\
\hline${ }^{81} \mathrm{Po}^{212}$ & 8,78 & & 100 & & \\
\hline \multirow[t]{6}{*}{${ }^{81} \mathrm{Tl}^{208}$} & & 1,04 & 4,6 & 0,277 & 7 \\
\hline & & 1,29 & 24 & 0,511 & 23 \\
\hline & & 1,52 & 23 & 0,583 & 86 \\
\hline & & 1,80 & 49 & 0,763 & 2 \\
\hline & & & & 0,860 & 12 \\
\hline & & & & 2,615 & 100 \\
\hline${ }^{82} \mathrm{~Pb}^{208}$ & \multicolumn{5}{|c|}{ Estável } \\
\hline
\end{tabular}

Fonte: Adams e Gasparini (1970).

\section{II.2 Alcance de partículas Alfa}

Uma partícula carregada, ao passar através de uma substância (alvo) pode interagir com elétrons carregados negativamente e com núcleos de átomos ou moléculas carregados positivamente (CNEN, 2003). Essas partículas, à medida que penetram na matéria, sofrem colisões e interações com perda de energia até que, a uma dada espessura do material, toda energia é dissipada e a partícula, portanto, para de se deslocar.

As partículas alfa que inicialmente possuem a mesma energia são denominadas monoenergéticas e percorrem distâncias aproximadamente iguais na matéria. $\mathrm{O}$ alcance médio (em centímetros) de uma partícula alfa no ar (em condições normais) com energia entre 4 e 10 $\mathrm{MeV}$, pode ser dado pela seguinte equação empírica (WILLIAMS 2009):

$$
\mathrm{R}=0,325 \mathrm{E}^{3 / 2}
$$


Sendo R o alcance, em [cm] e E a energia da partícula alfa, em MeV. A Fig. 1 mostra o gráfico da Equação 1.

Pode-se observar na Tabela 1 que as energias das partículas alfa emitidas na série do Tório-232 variam de 3,95 MeV a 8,78 MeV. Utilizando a Equação 1 podemos obter os alcances no ar destas partículas, que variam de $2,55 \mathrm{~cm}$ a $8,46 \mathrm{~cm}$, conforme cálculos a seguir.

Para $\mathrm{E}=3,95 \mathrm{MeV}$, tem-se $\mathrm{R}=0,325 \times 3,95^{3 / 2}=2,55 \mathrm{~cm}$.
Para $\mathrm{E}=8,78 \mathrm{MeV}$, tem-se $\mathrm{R}=0,325 \times 8,78^{3 / 2}=8,46 \mathrm{~cm}$.

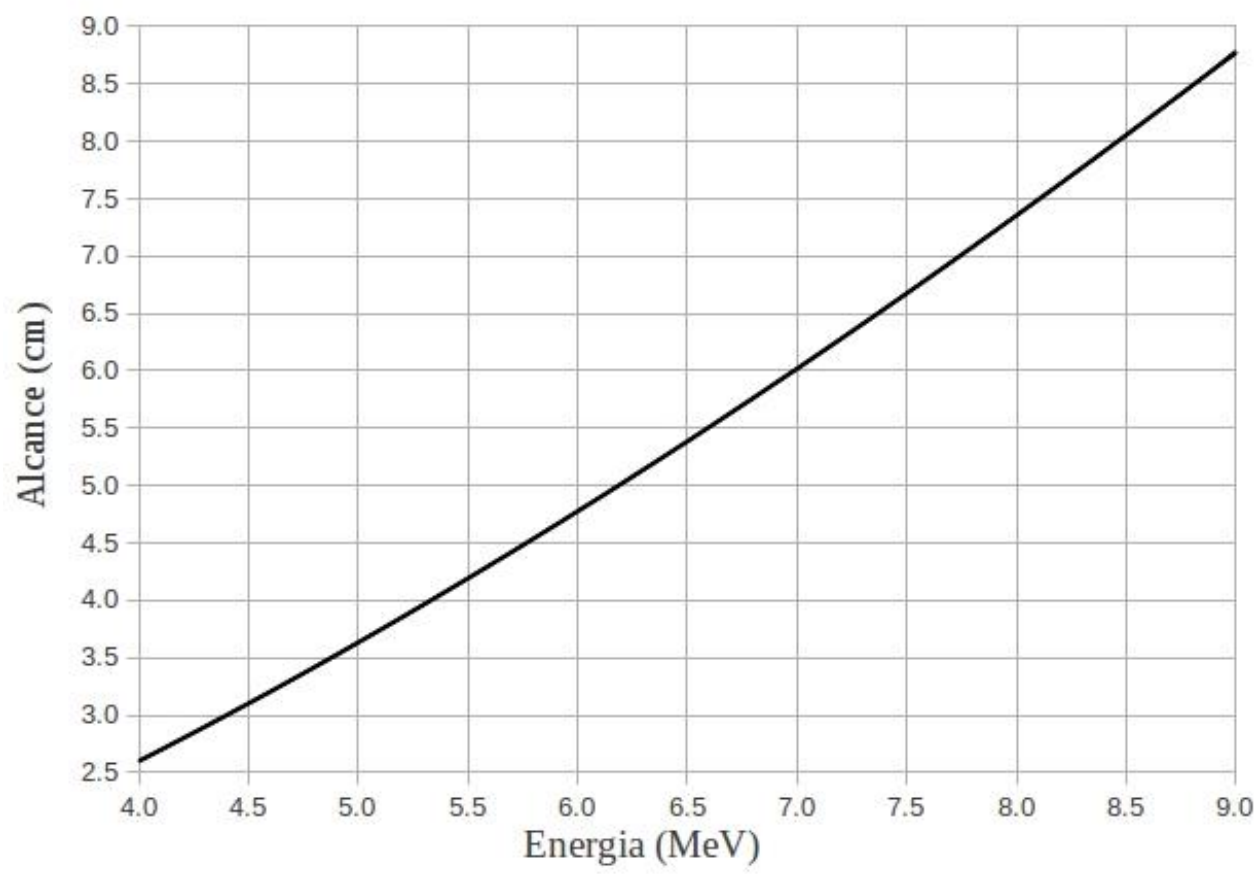

Fig. 1 - Gráfico do alcance da partícula alfa no ar em função da energia, de acordo com a Equação 1.

\section{II.3 Filhos de Radônio-222 coletados por filtragem}

Geralmente, materiais radioativos estão ligados a sólidos, como por exemplo, isótopos radioativos de Urânio, Tório ou Rádio presos no concreto e no solo. Estes materiais radioativos decaem para elementos mais leves.

Na série do Urânio-238 um dos filhos é o radônio-222, um gás nobre radioativo, quimicamente inerte e que não permanece ligado ao sólido da mesma forma que seus pais. Ele se difunde através do sólido e pode emanar para a atmosfera. Todos nós aspiramos um pouco de radônio a cada vez que aspiramos o ar, mas logo em seguida o expiramos. Apenas uma pequena fração do Radônio-222 decai dentro dos pulmões a cada ciclo de respiração, pois o Radônio-222 tem meia vida de 3,6 dias e o ciclo dura alguns segundos.

O Radônio-222 emite partículas alfa de energia 5,49 MeV, decaindo para radioisótopos mais leves na seguinte sequência: Polônio-218, Chumbo-214, Bismuto-214, e Polônio-214. 
O Polônio-218, de meia-vida de 3,0 minutos, também é emissor alfa, de energia 6,0 $\mathrm{MeV}$. Depois, o polônio decai para o Chumbo-214, de meia vida de 26,8 minutos, emissor beta, que decai para o Bismuto-214, de meia vida 19,7 minutos, também emissor beta. O próximo elemento da série é o Polônio-214 de meia vida $1,6 \times 10^{-4} \mathrm{~s}$, também emissor alfa de energia $7,68 \mathrm{MeV}$.

Como os filhos do Radônio-222 não são gases nobres, caso sejam produzidos na atmosfera, eles irão se ligar a alguma superfície ou à pequenas partículas de poeira e aerossóis. Assim, eles podem ser coletados através de um filtro de ar. Este filtro se tornará em uma fonte de intensidade geralmente suficiente para a realização de medidas de radiação com a câmara de ionização.

\section{Propostas experimentais}

\section{III.1 - Mapeamento da concentração dos filhos do Radônio-222 no ar ambiental}

Esta atividade consiste em filtrar os aerossóis do ar de diferentes ambientes internos e verificar a presença dos filhos de radônio utilizando a câmara de ionização. Se a coleta por filtragem for feita nas mesmas condições, uma comparação das concentrações de filhos no ar poderá ser feita ao se comparar os valores indicados pela câmara de ionização para diferentes ambientes.

Este procedimento poderá ser realizado em qualquer ambiente (sala de aula, laboratório, banheiro, cozinha, área de serviço, etc.), utilizando a câmara de ionização, filtro (gazes) e uma "bomba de vácuo" (aspirador de pó, secador de cabelo, cooler adaptado Figura 2a e 2b).

Para fazer a coleta utilizando o aspirador de pó, basta colocar o filtro na extremidade onde o ar será sugado, para realizar a filtragem. No secador de cabelo, o filtro deve ser colocado onde o ar entra, ou seja, no lado contrário de onde o ar aquecido sai.

O cooler adaptado (Fig. 2) é uma versão semelhante à também proposta por Wenzel (WENZEL, 2014), feita para realizar as coletas dos filhos de Radônio-222 nos ambientes estudados. Foram utilizados na construção: uma lata de leite em pó, cola epóxi, tela metálica, fita adesiva e um cooler de $12 \mathrm{~V}$. Inicialmente retira-se o fundo da lata e cola-se o cooler com epóxi, na outra extremidade da lata, prende-se um pedaço de tela $(12 \mathrm{~cm} \mathrm{x} 12 \mathrm{~cm})$, com fita adesiva, para que sirva de apoio ao filtro.

Para que a coleta dos filhos do Radônio-222 seja realizada basta ligar a "bomba de vácuo". Em geral, cerca de 5 minutos de coleta são suficientes, em especial se o ambiente interno estiver fechado por mais de 12 horas. Depois da coleta basta expor o filtro à câmara de ionização.

As indicações do multímetro devem ser anotadas com o filtro posicionado logo em frente da janela com a tela antes e depois da filtragem. A medida do filtro antes da execução da 
filtragem representa a medida de fundo, também chamada de branco. Se a voltagem no multímetro aumentar na medida do filtro depois da filtragem do ar, está comprovada a presença dos filhos do radônio nos aerossóis coletados. Anotando-se a voltagem máxima do multímetro ao medir os filtros utilizados em diferentes ambientes, torna-se possível comparar a radioatividade do ar desses ambientes.

As medidas devem ser feitas imediatamente depois da coleta, pois alguns minutos já são suficientes para a diminuição da atividade do filtro, já que um dos emissores alfa filhos do Radônio-222, o Polônio-218, tem meia-vida de 3,0 minutos.

a)

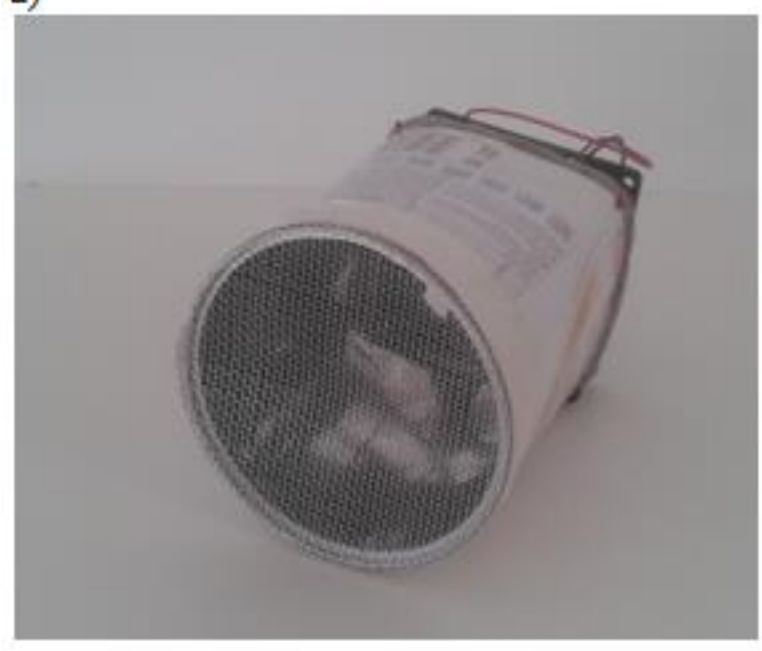

b)

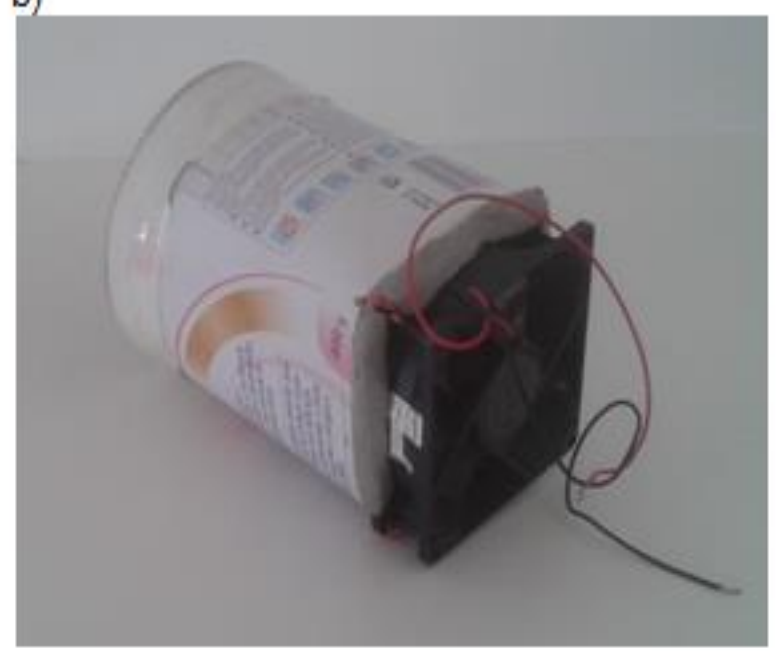

Fig. 2 - a) Cooler adaptado com janela de tela metálica. b) Cooler adaptado visto em outro ângulo.

Essa prática possibilita aos alunos e ao professor realizar a coleta de material radioativo de baixa intensidade nas salas de aula e com isso poderão ser trabalhados os mais variados assuntos envolvidos como: séries radioativas, decaimento, tipos de radiação, meia-vida, etc.

Para ilustrar alguns resultados, medidas dos filhos do Radônio-222 foram obtidas à partir de coletas realizadas em diferentes locais. A Tabela 2 mostra os resultados obtidos. Para todas as coletas os filtros utilizados foram gazes. As coletas foram feitas com o uso ou de aspirador de pó, ou secador de cabelo ou o cooler adaptado, conforme indica a Tabela 2.

Os locais escolhidos estavam ou foram fechados por pelo menos $12 \mathrm{~h}$, para que as coletas fossem realizadas, e conforme se observa, na maioria dos locais foi possível detectar os filhos do Radônio-222 com a câmara de ionização. 
Tabela 2 - Locais de coleta dos filhos de Rn-222. * Voltagem indicada no multímetro antes e depois da coleta. **Abaixo do limite de detecção da câmara.

\begin{tabular}{|l|l|l|l|}
\hline Local da coleta & Coletor utilizado & Filtro antes* & Filtro depois* \\
\hline - Quarto de hóspedes & Secador de cabelo & $1,72 \mathrm{~V}$ & $1,78 \mathrm{~V}$ \\
\hline - Garagem & Secador de cabelo & $1,70 \mathrm{~V}$ & $1,80 \mathrm{~V}$ \\
\hline - Embaixo da escada & Cooler adaptado & $1,73 \mathrm{~V}$ & $1,80 \mathrm{~V}$ \\
\hline - Área de serviço** & Cooler adaptado & $1,72 \mathrm{~V}$ & $1,72 \mathrm{~V}$ \\
\hline - Banheiro** & Cooler adaptado & $1,72 \mathrm{~V}$ & $1,72 \mathrm{~V}$ \\
\hline - Dentro da Churrasqueira & Aspirador de pó & $1,72 \mathrm{~V}$ & $1,82 \mathrm{~V}$ \\
\hline
\end{tabular}

Os locais escolhidos estavam ou foram fechados por pelo menos $12 \mathrm{~h}$, para que as coletas fossem realizadas, e conforme se observa, na maioria dos locais foi possível detectar os filhos do Radônio-222 com a câmara de ionização.

\section{III.2 Medida do alcance das partículas alfa emitidas pela camisinha de lampião}

Esta prática consiste em verificar que ao aproximar a fonte radioativa da janela da câmara de ionização, a voltagem no multímetro começa a aumentar quando a fonte está a determinada distância. Isto indica que, nesta distância específica, as partículas alfa começam a atingir o volume sensível da câmara, ionizando o ar dentro da mesma. Esta distância corresponde ao alcance máximo das partículas alfa emitidas pela fonte. Conforme já explicado, esta distância permite estimar, através da Equação 1, a energia da partícula alfa detectada.

A prática pode ser realizada utilizando os seguintes materiais: câmara de ionização, régua $(30 \mathrm{~cm}$ ou $50 \mathrm{~cm})$, papel, caneta ou lápis, fita adesiva, suporte (para prender a camisinha) e camisinha de lampião. Para a realização dessa prática deve-se primeiramente fixar a régua na mesa ao lado ou sob a câmara de ionização, e também fixar a camisinha com fita adesiva no suporte, qualquer objeto que facilite a aproximação da fonte à câmara (veja um exemplo na Figura 3a). Após ligar a câmara de ionização deve-se esperar a indicação no voltímetro estabilizar (Figura 3b) e assim, aproximar lentamente, de $1 \mathrm{~cm}$ em $1 \mathrm{~cm}$, a camisinha da câmara de ionização, e anotar os valores indicados no voltímetro.

Com os dados encontrados é possível descobrir qual o filho do Tório-232 é responsável pela emissão da radiação alfa de maior energia. Ao realizar essa prática assuntos como alcance das partículas, energia das partículas, interação com a matéria, decaimento e fissão nuclear, poderão ser trabalhados em sala. 
a)

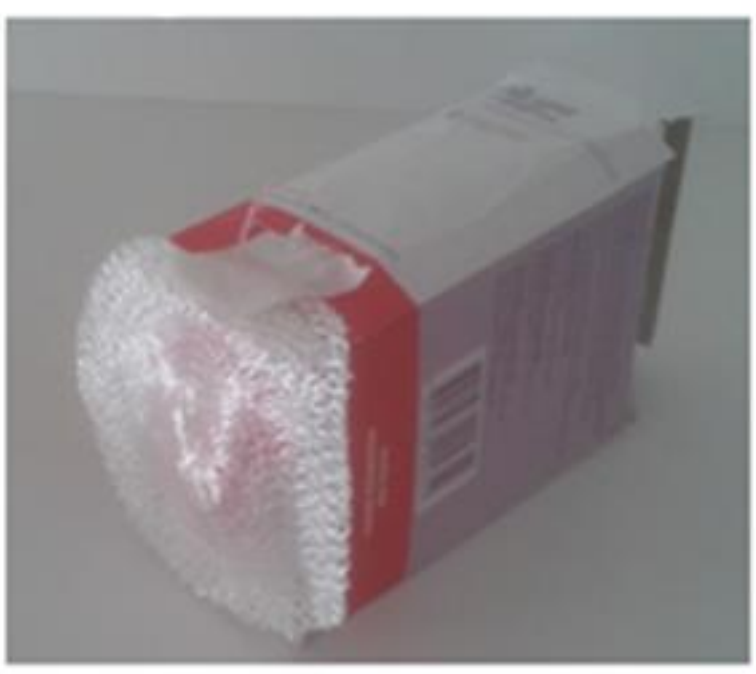

b)

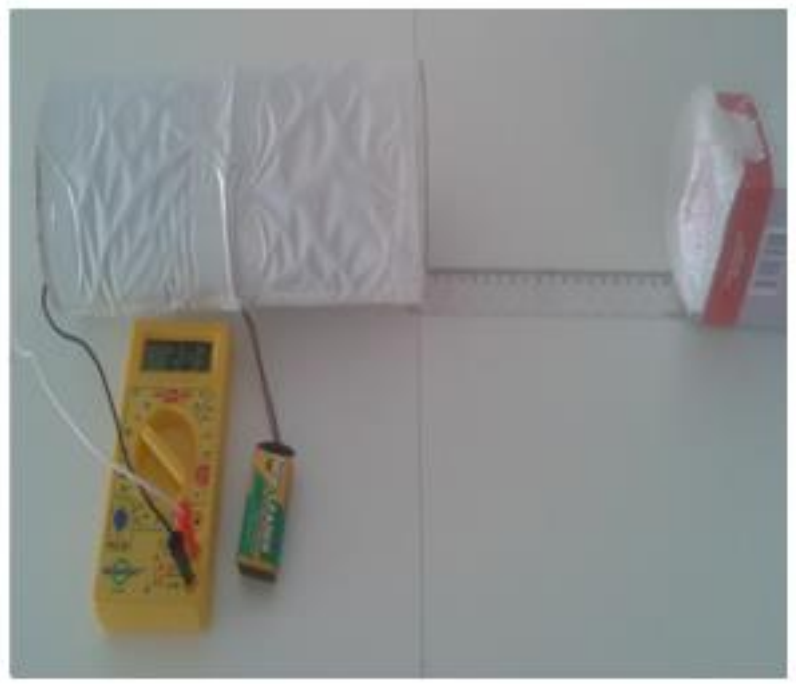

Fig. 3 - a) Camisinha de lampião presa no suporte (uma caixa de remédio neste caso). b) Câmara de ionização ligada com a fonte a $20 \mathrm{~cm}$ de distância.

A Fig. 4 mostra os dados coletados ao realizar o experimento.

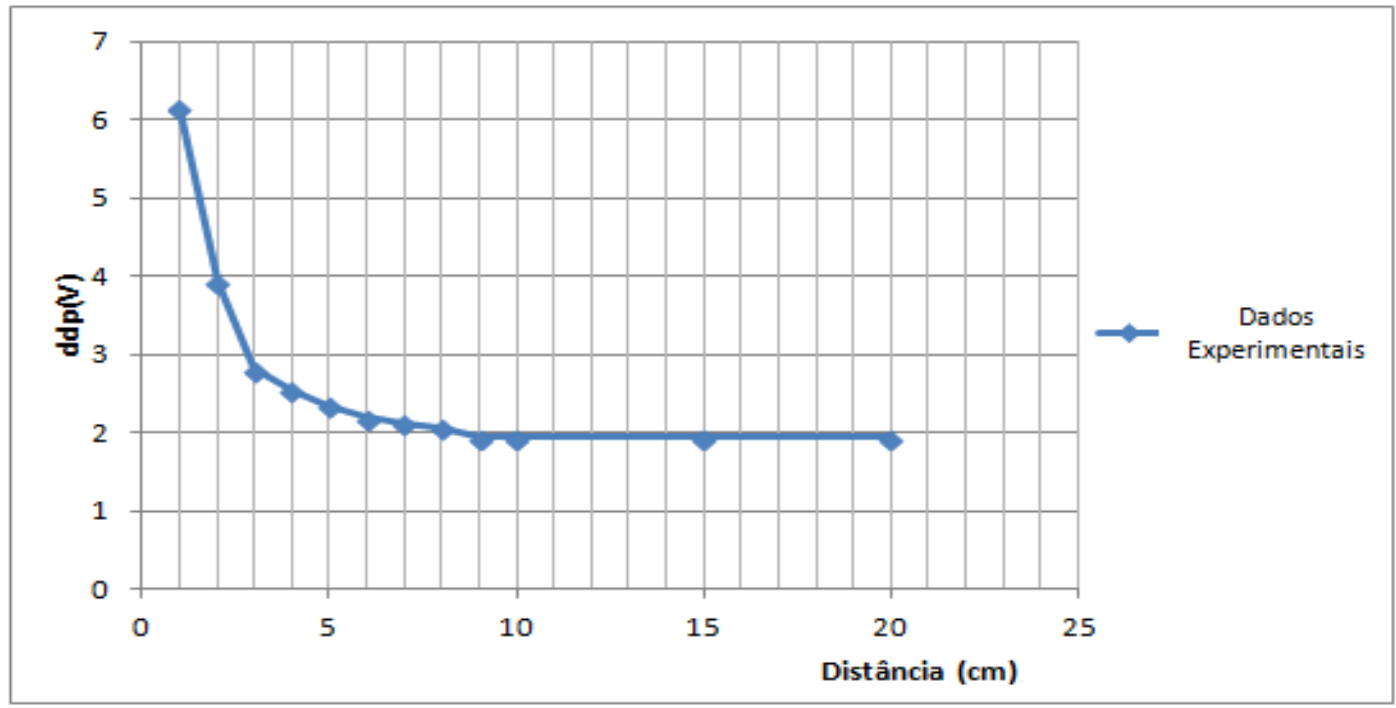

Fig. 4 - Gráfico da medida da voltagem no detector em função da distância entre o detector e a camisinha.

Fica evidente na Fig. 4 que a câmara de ionização começa a detectar partículas alfa entre 8 e $9 \mathrm{~cm}$ (com margem de erro de $\pm 1 \mathrm{~cm}$ ), posição em que a voltagem descola do valor de estabilidade. $\mathrm{O}$ erro se deve em parte, à posição em que a camisinha de lampião é colocada sobre a régua. Esta posição não é exata devido a sua forma irregular. As energias correspondentes a esse intervalo de alcances podem ser verificadas na Fig. 1, e são de 
aproximadamente 8,5 a 9,0 MeV. Podemos reconhecer na Tabela 1 que o nuclídeo responsável por essa emissão é o Polônio-212 que emite radiação alfa de energia $8,78 \mathrm{MeV}$.

Conforme se aproxima a fonte do detector, a tensão indicada continua a aumentar. Isso se dá por três motivos. Um deles é o aumento da eficiência geométrica. Como a camisinha é uma fonte difusa, não colimada, ela emite partículas alfa em todas as direções. Ao aproximar a camisinha do detector, mais partículas alfa, de mesma energia das que foram inicialmente detectadas, atingem o volume sensível da câmara, melhorando a eficiência de detecção. Outro motivo para o aumento de tensão é que as partículas alfa, inicialmente detectadas a distâncias maiores, passam a perder uma parte maior de sua energia dentro da câmara, pois suas trajetórias avançam para o interior do detector na medida em que aproximamos a fonte do detector. E o terceiro motivo para o aumento da tensão é que, a distâncias menores, ocorre a detecção de outras partículas alfa, menos energéticas, provenientes de outros filhos do Th-232, e do próprio Th-232. Isso pode ser percebido mais claramente no gráfico entre as distâncias 2 e $3 \mathrm{~cm}$, onde a inclinação da curva fica mais pronunciada se comparada com a inclinação a distâncias maiores. É neste intervalo de distâncias (2 a $3 \mathrm{~cm}$ ) que as partículas alfa de $4 \mathrm{MeV}$, emitidas pelo próprio Th-232, alcançam o interior da câmara de ionização.

\section{Considerações finais}

O presente trabalho propôs práticas experimentais de baixo custo para o ensino de Física Nuclear utilizando uma câmara de ionização confeccionada também com material de baixo custo.

As fontes radioativas utilizadas estão de acordo com a problemática apresentada, ou seja, possuem meia vida curta e/ou são de baixa intensidade, além de serem acessíveis aos vários níveis de ensino. As câmaras de ionização se mostram sensíveis e estáveis o suficiente para medir a radiação emitida pelas fontes.

Mesmo sabendo que a maioria dos materiais didáticos não aborda vários assuntos de Física Nuclear envolvidos nos experimentos, é possível realizar uma adaptação dos conteúdos, incluindo-os, e realizar as práticas propostas em aula. Um exemplo de proposta pedagógica utilizando este material pode ser visto em Boff (2016).

Uma consideração importante é que a manipulação das fontes radioativas requer alguns cuidados. Mesmo tendo baixa intensidade as fontes emitem radiação ionizante. Assim, é recomendável evitar o contato da camisinha de lampião com a pele, armazená-la em local seguro e deixá-la fora do alcance de crianças.

\section{Referências Bibliográficas}

ADAMS, J. A. S., GASPARINI, P. Gamma-Ray Spectrometry of Rocks. Elsevier Publishing Company, Amsterdam/London/New York. 1970. P.104-129. 
BOFF, C. A., BASTOS, R. O., MELQUIADES, F. L. Construção e Caracterização de um detector de ionização gasosa para Instrumentação no Ensino de Física Nuclear. In: SIMPÓSIO NACIONAL DE ENSINO DE CIÊNCIAS E TECNOLOGIA, IV, 2014, Ponta Grossa, PR. Disponível em: <http://sinect.com.br/anais2014/anais2014/artigos/ensino-de-fisica/ 01408324160.pdf> Acesso em: 12 nov. 2016.

BOFF, C. A. Construção de um detector de ionização gasosa com material de baixo custo para práticas experimentais no ensino de física nuclear. 2016. 109f. Dissertação (Mestrado Profissional em Ensino de Ciências Naturais e Matemática) - UNICENTRO, Guarapuava, PR.

CNEN, Apostila Educativa. Aplicações da Energia Nuclear. Rio de Janeiro, 2003. Disponível em: 〈http://www.cnen.gov.br/ensino/apostilas/aplica.pdf>. Acesso em: 10 mai. 2015.

CNEN, Apostila Educativa. Energia Nuclear. Rio de Janeiro, 2003. Disponível em: <http://www.cnen.gov.br/ensino/apostilas/energia.pdf>. Acesso em: 10 mai. 2015.

CNEN, Apostila Educativa. Radiações Ionizantes e a vida. Rio de Janeiro 2003. Disponível em: 〈http://www.cnen.gov.br/ensino/apostilas/rad_ion.pdf>. Acesso em: 10 mai. 2015.

CNEN, Apostila Educativa. Radioatividade. Rio de Janeiro 2003. Disponível em: <http://www.cnen.gov.br/ensino/apostilas/radio.pdf>. Acesso em: 10 mai. 2015.

CNEN, Apostila Educativa. A Energia Nuclear e suas aplicações. Rio de Janeiro 2003. Disponível em: <http://www.cnen.gov.br/ensino/apostilas/energia_aplic.pdf>. Acesso em: 10 mai. 2015.

SILVA, N. C. Laboratório virtual de Física Moderna: Atenuação da radiação pela matéria. Caderno Brasileiro de Ensino de Física, v. 29, n. 3, p. 1206-1231, 2012.

SILVA, N. C. Laboratório virtual de Física Moderna: sistema para espectrometria gama. Caderno Brasileiro de Ensino de Física, v. 32, n. 2, p. 542-562, ago. 2015.

VICENTE, R. Gestão de fontes radioativas seladas descartadas. 2002. $124 \mathrm{f}$. Tese (Doutorado em Ciências na Área de Tecnologia Nuclear Aplicações) - Instituto de Pesquisas Energéticas e Nucleares, Autarquia Associada à Universidade de São Paulo, São Paulo.

WENZEL, C. Radon Detector for the Student. Disponível em: <http://www.techlib.com/science/ionchamber.htm>. Acesso em: 01 mar. 2014.

WILLIAMS, T. Alpha and beta ranges. 2009. Disponível em: <www.alpharubicon.com/basicnbc/article16radiological71.htm>. Acesso em: 25 nov. 2016. 